\title{
Numerical Analysis of the New Forming Process of the Aircraft Bracket Forging Made of AZ91 Alloy at Different Rates of Deformation
}

\author{
Anna DZIUBIŃSKA*, Piotr SURDACKI
}

\begin{abstract}
The article presents the results of numerical simulations of the new forging process of the aircraft bracket forging at different deformation rates related to the type of machine used: a hydraulic press, a screw press and a drop forging hammer. The billet of shaped preforms from AZ91 alloy with two different geometries was used for the process. It was assumed that forging a bracket from an unformed, shaped preform will have a positive effect on the kinematics of the flow and on the deformation capability of AZ91 magnesium alloy, and will reduce the number of operations necessary to obtain the correct item. The numerical analysis of the new process was carried out with FEM, using the software Deform 3D. Based on the simulation, the important information about the process was obtained, that is the distribution of stress, deformation, temperatures, cracking and force parameters. The obtained results of numerical tests confirmed the possibility of producing the correct aircraft brackets forgings from AZ91 magnesium alloys with the proposed technology.
\end{abstract}

Keywords: aircraft bracket; cast preform; computer simulations; FEM; forging; magnesium alloys

\section{INTRODUCTION}

Only continuous investment in research and innovation of aircraft design can meet future requirements of the aeronautical framework [1-3]. The aircraft part was selected for the investigation, a bracket made of AZ91 magnesium alloy (Fig. 1). This part is currently manufactured by milling a prism-shaped magnesium cast. This technology causes significant material losses and requires a long machining time, and the mechanical and functional properties of the manufactured parts are not satisfactory. Another method of manufacturing a bracket is forging it from a rod with a diameter of $\varnothing 45$ and a length of $160 \mathrm{~mm}$ [4]. It is an equally long and material-consuming process (the flash exceeds $60 \%$ of the volume of the forging). Occasionally, it proves impossible to obtain the correct product using this method from magnesium alloys which are difficult to deform. It happens that the forgings produced from a rod have cracks, especially during their multi-stage deformation from the formed billet. Therefore, an attempt was made to develop a new technology of forging bracket forgings from cast preforms.

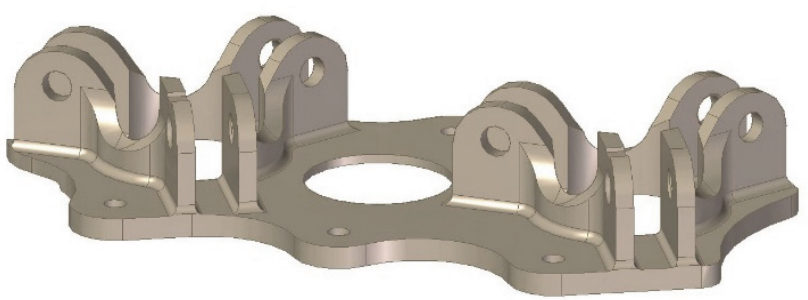

Figure 13D drawing of a magnesium alloy aircraft bracke

Magnesium alloys are widely used in the automotive, aeronautical and aerospace industries [5, 6]. Their main advantage is meeting the strength requirements while ensuring the low weight of the product. Recently, the interest in the use of magnesium alloys in industry has significantly increased. The most commonly used magnesium alloys are AZ, AM, EZ, ZK and WE series, mostly as casting alloys [7]. The most popular casting magnesium alloy is AZ91 [7]. Its main components are aluminium, zinc and manganese.
The addition of aluminium improves hardness, flowing properties and increases tensile strength. The addition of zinc, in turn, increases the strength at room temperature, and the addition of manganese improves the anti-corrosion properties [8]. AZ91 alloy has good strength properties and good flowing power; unfortunately, the relatively high aluminium content significantly affects forming properties $[9,10]$. This alloy shows superplasticity at low temperature for the grain size below $10 \mu \mathrm{m}$ [11].

Drop forging is one of the oldest and most frequently used metal forming technologies. This method makes it possible to obtain forgings with a complex shape and good strength parameters. Due to its high efficiency and the possibility of forming products from various types of materials with different geometries, drop forging is widely used in large-scale production in many industries, for instance in aviation, automotive, agricultural or mining. This technology is characterised by a relatively low material consumption, but in order to increase the efficiency of the process, efforts are made to minimise the material consumption even further, which translates into a reduction in production costs. Optimisation of the discussed technology allows to increase the material yield, and as a consequence reduce the number of operations. Forming preforms directly on the forging die requires great skill and many operations. One of the options for obtaining a suitable preform is forge rolling. In the study [12], the process of forming the preform made of AZ31 magnesium alloy was analysed using the longitudinal rolling method. The authors proved the validity of using this technology and stated that it is possible to avoid material cracking by using an appropriate tool geometry. Another process often encountered in the production of preforms or finished products is the cross-wedge rolling. It ought to be noted that this is an efficient and repeatable process, however, it is exposed to the occurrence of material cracks which may occur in the axis of the rolled preform [13]. Recently, the development of research on determining the appropriate shape of the preform has been noticeable. Thanks to the development of numerical methods, special tools are created which enable generating the optimal geometry of the billet [14]. The casting technology is also used to achieve the appropriate geometry of the preform. 
Combining casting as a technology for obtaining a preform and forging as a technology for obtaining the final item gives good results. During the production with the use of both technologies, the following stages are distinguished: preparation of the cast, its heat treatment and forging. Castings make it possible to manufacture products of complex geometry from hard-deforming materials. The forging technology allows for the final forming of the forgings and the improvement of its strength parameters. In specialist literature the descriptions of such production can be found, for example, of flanges [15], suspension arms [16] or pistons [17] with the use of various types of material, such as magnesium alloys AZ70 [18] or steel [19, 20].

The process of forging magnesium forgings is most often carried out with the use of three forging machines: a hydraulic press [21-24], a drop hammer [4, 24-26] and a screw press [4]. Each of these machines has the different operating characteristics. Drop hammers form the material in a dynamic way, causing, among others, the phenomenon of inertial filling of the forging step. The material flows more superficially. The advantage of these forging machines is their high versatility $[27,28]$.

In drop forging on screw presses, the energy of the drive system is converted into useful work by means of a non-self-locking screw mechanism. An important feature of screw presses is the lack of kinematic restrictions for the movement of the slide. This means that the forging process can be carried out until the dies are in contact. As a result, the dimensional accuracy of the forgings in terms of their height is the best among all forging methods. If the impact energy of the die is too low for the dies to touch each other completely, the impact is repeated. This possibility eliminates the likelihood of underforging. Screw presses are suitable for forging both in open and in closed dies. Setting the die is an easy and streamlined operation, as there is not any need to adjust the height of the closed die. It is related to the lack of precise setting of the lower position of the slider. The greatest advantage of screw presses is the linear speed of the slider, where the highest value of $0,6-1,5 \mathrm{~m} / \mathrm{s}$ is achieved at the moment of contact of the dies (that is in the final stage of forging). An impact at such a speed causes stresses in the dies which are $5-10$ times lower than during forging with hammers [27].

Among the forming machines, hydraulic presses are characterised by the highest possible pressure values of their working sliders. The main advantages of hydraulic presses include: simple construction of the machine, easy adjustment of the stroke and position of the slider, the possibility of smooth compensation of elastic deformations of the body and tools, high accuracy of the operations performed, constant speed of the slider and constant working pressure in the entire range of the slider stroke [28, 29].

Based on the analysis of the literature, the use of preforms in drop forging processes seems to be the current research direction. There are various methods of manufacturing the preforms, which are generally divided into two groups: formed and cast. In view of the above, it is justified to conduct further research on the forging process from the cast preforms. The aim of the article is a comparative analysis of the forging process on three forging machines: a drop hammer, a hydraulic press and a screw press for forging of a bracket with the use of cast preforms, ensuring a different degree of forging. The conducted research has shown that the use of a preform significantly increases the efficiency of the process in terms of, for instance, material consumption compared to traditional forging with a billet in the form of a rod.

\section{REASEARCH MEDHODOLOGY}

For the bracket selected for testing, the geometry of the forging has been developed as shown in Fig. 2. It was assumed that the new process of forging AZ91 bracket forgings would be carried out from the billet of formed cast preforms. Two geometries of the preforms were developed, one with a lower degree of forging (variant 1, Fig. 3a) and another with a higher degree of forging (variant 2, Fig. 3b) respectively. Preforms differ mainly in the height and dimensions of their cross-sections.

The main objective of the computer simulations was a comparative analysis of the process carried out on different machines with different deformation rates. It was assumed that the process of forging a bracket forging from a formed cast preform would be carried out in a single operation in a finishing impression. The numerical analysis of the new process was carried out on the basis of the finite element method (FEM), using the Deform 3D version 11.0 commercial software package. The simulations were carried out in the conditions of the spatial state of deformation, considering the full thermomechanical analysis. Based on the simulation, the important information about the process was obtained, including the distribution of stress, deformation, temperatures, cracking criteria, kinematics of the flow and force parameters. It was assumed that the preforms made of AZ91 alloy with a chemical composition in (Tab. 1) would be produced from sand moulds casts.

The material model of the cast AZ91 magnesium alloy was developed on the basis of own plastometric tests carried out on the DIL $805 \mathrm{~A} / \mathrm{D}$ deformation dilatometer. The results obtained from plastometric tests were coded to the program in tabular form and subjected to the deformation rate in the range from $0,01 \mathrm{~s}^{-1}$ to $10 \mathrm{~s}^{-1}$, temperature in the range of $240-440{ }^{\circ} \mathrm{C}$, and the deformation value in the range between $0-1$.

The calculations assume that the charge is heated to a temperature of $420{ }^{\circ} \mathrm{C}$, and the temperature of the dies during the process is constant and equal to $250{ }^{\circ} \mathrm{C}$. The geometry of the preforms was divided into 150000 tetragonal elements. A heat transfer coefficient of 4,5 $\mathrm{kW} / \mathrm{m}^{2} \mathrm{~K}$ between the formed material and tools was assumed, and $0,03 \mathrm{~kW} / \mathrm{m}^{2} \mathrm{~K}$ between the surroundings and the material [30]. In the calculations, a model of constant friction was adopted, in which the friction factor corresponding to the contact conditions between magnesium alloy and steel with graphite grease lubrication is $\mu=0,24$ [17]. For the hydraulic press, the speed of movement of the upper die was assumed to be $10 \mathrm{~mm} / \mathrm{s}$. For a drop hammer, the assumed impact energy equalled to $36 \mathrm{~kJ}$, the weight of the falling part was $1000 \mathrm{~kg}$ and its efficiency 0,8 , and for a screw press - energy $40 \mathrm{~kJ}$, efficiency 0,8 . 


\begin{tabular}{|l|l|l|l|l|l|l|l|l|}
\hline \multicolumn{10}{l|}{ Table 1 Chemical composition of AZ91 alloy / \% by weight } \\
\hline Al & Zn & Mn & Fe & Si & Cu & Be & Ni \\
\hline 9,03 & 0,6 & 0,2 & 0,0026 & 0,0023 & 0,0016 & 0,0011 & 0,00062 \\
\hline
\end{tabular}

a)

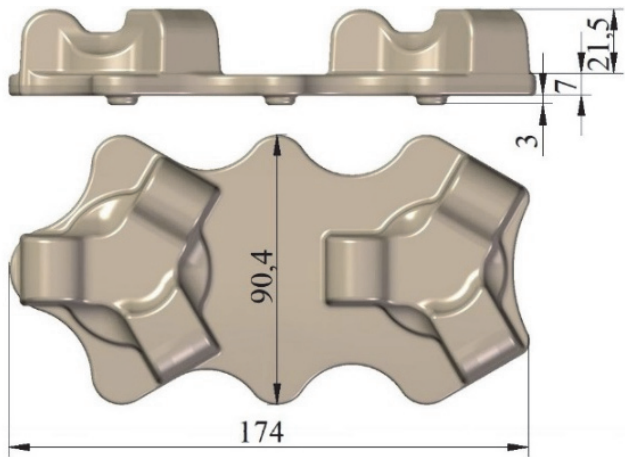

Figure 2 Selected dimensions of the bracket forging, a) side view, b) top view

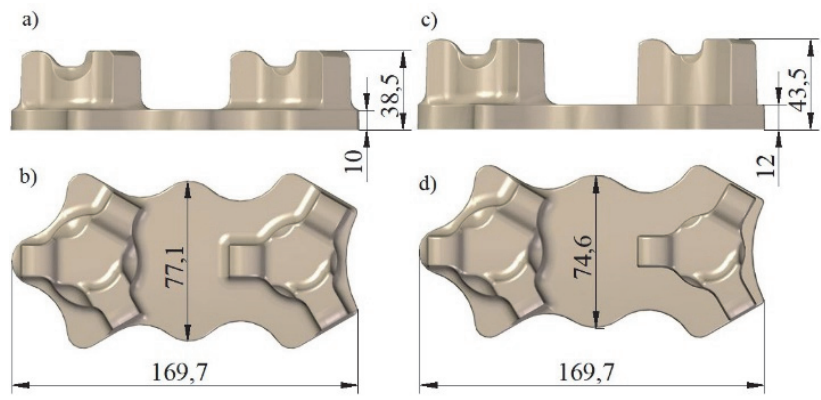

Figure 3 Selected dimensions of the preforms, a) variant I, side view, b) variant $\mathrm{I}$, top view, c) variant II, side view, d) variant II, top view

\section{ANALYSIS OF THE RESULTS}

An example of the process of forging a bracket forging on a drop hammer from a cast preform with a higher degree of forging is shown in Fig. 4. Fig. 5 shows the progression of forming the forgings from two geometries of cast preforms depending on the degree of process advancement. For both of the proposed preform geometries, the forging steps are filled mainly by upsetting, which seems to be advantageous. In both cases, the forging steps were filled with material, as evidenced by the appearance of flash. The analysis of the presented results indicates that it is not too thick and that it evenly filled the bridge and the ejector along the contour of the forgings in the division plane, which is advantageous both in terms of technology and economy.

a)

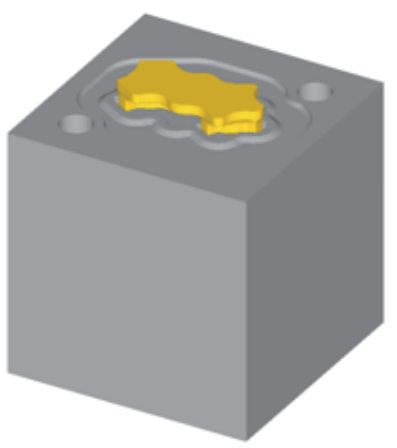

Figure 4 Scheme of the process of forging a bracket forging from a preform variant II on a drop hammer, a) start of the process, b) end of the process, (upper die has been hidden to better illustrate the process)
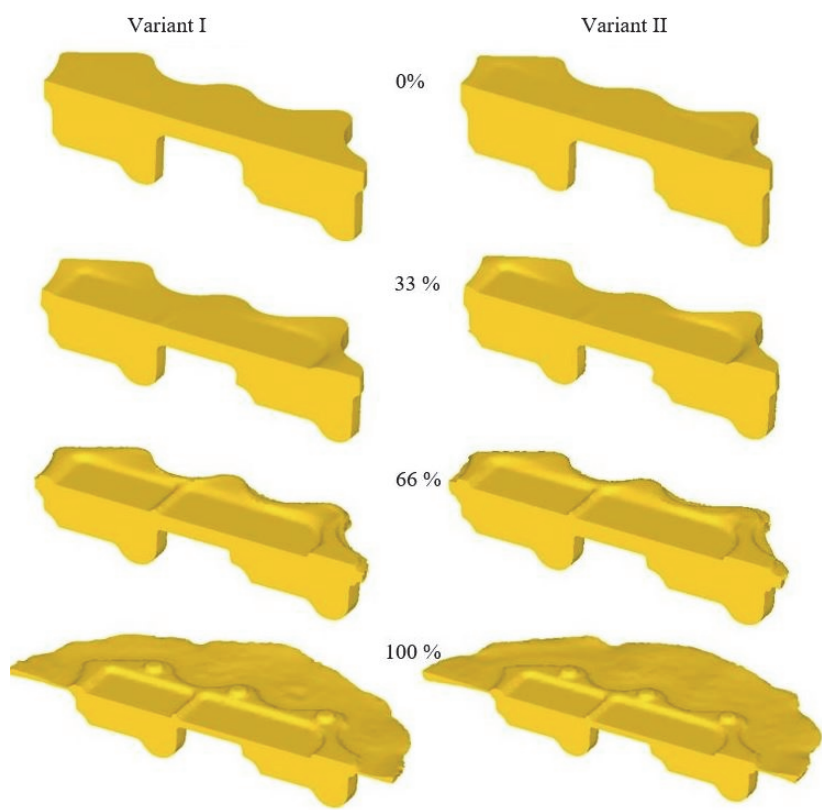

Figure $\mathbf{5}$ Scheme of the process of forging a bracket forging from a preform

Fig. 6 to Fig. 13 show the results of the numerical calculations of the forging process of the bracket forging from the billet in the form of cast preforms, carried out for three forging machines (a hydraulic press, a drop hammer, a screw press). The figures show the stress and strain intensity distributions, temperature, Cockcroft-Latham integral values.

Fig. 6 and Fig. 7 show the stress intensity distribution for the tested variants of cast preforms on three machines. The heterogeneous distribution of this parameter throughout the forging is visible. For all variants, the highest stress value was obtained in the bracket's ribs, respectively about $70 \mathrm{MPa}$ for a hydraulic press, $90 \mathrm{MPa}$ for a drop hammer and $80 \mathrm{MPa}$ for a screw press. The differences in values are related to the operating characteristics of individual machines. In the remaining areas of the forging, the stress intensity values are much lower and assume the values of $35 \mathrm{MPa}-45 \mathrm{MPa}$.

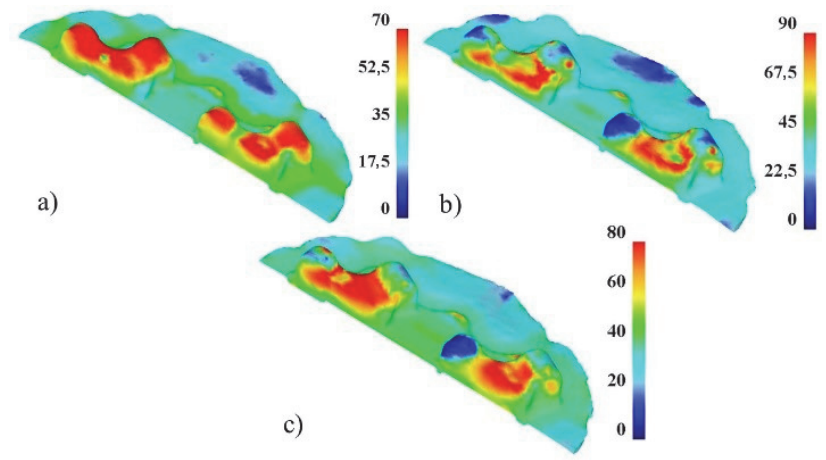

Figure 6 Distribution of the stress intensity (in MPa) in the bracket forging (bottom view) forged from the preform with a lower degree of forging on: a) a hydraulic press, b) a drop hammer, c) a screw press

For all analysed machines, the distribution of deformation intensity in the entire forging is also heterogeneous (Fig. 8 and Fig. 9), and the highest values of 
approx. 3,5 occur in the flash in the bridge area. Considering the forging, the highest value of deformation is close to 1,5 in the area of the base of the bracket, and for the ribs, the value of the considered parameter oscillates around 0,8 or less. The results allow for the conclusion that the deformation values for the two variants of preforms are similar.

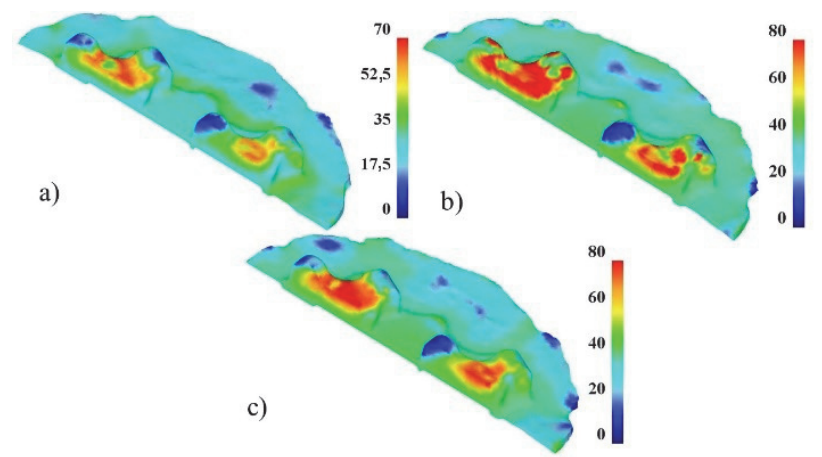

Figure 7 Distribution of the stress intensity (in $\mathrm{MPa}$ ) in the bracket forging (bottom view) forged from the preform with a higher degree of forging on: a) a hydraulic press, b) a drop hammer, c) a screw press

The forging temperature values for both variants of the preform (Fig. 10 and Fig. 11) oscillate around its initial value of $420^{\circ} \mathrm{C}$. The lowest values were obtained for the forgings forged on a hydraulic press, while the highest were obtained with a drop hammer which results from the dynamics of the analysed machines. For all considered variants, the temperature reaches its highest value in the flash, which is caused by the intense impact of friction and the greatest crush of the formed material.

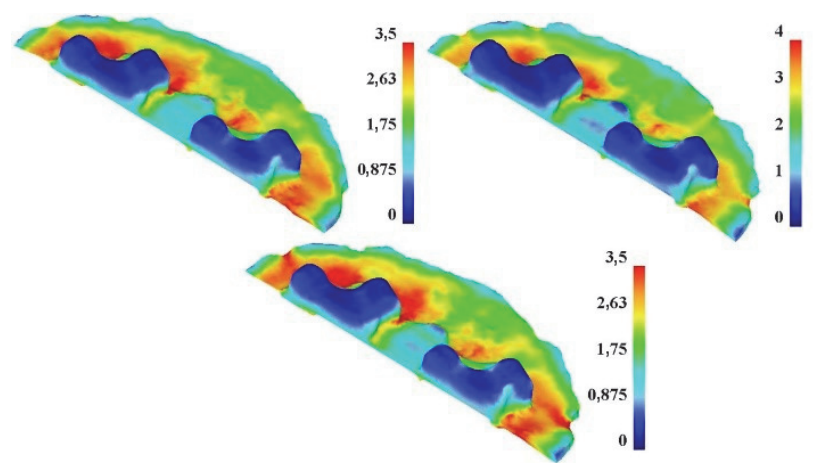

Figure 8 Distribution of the intensity of deformations in the bracket forging (bottom view) forged from the preform with a lower degree of forging on: a) a hydraulic press, b) a drop hammer, c) a screw press

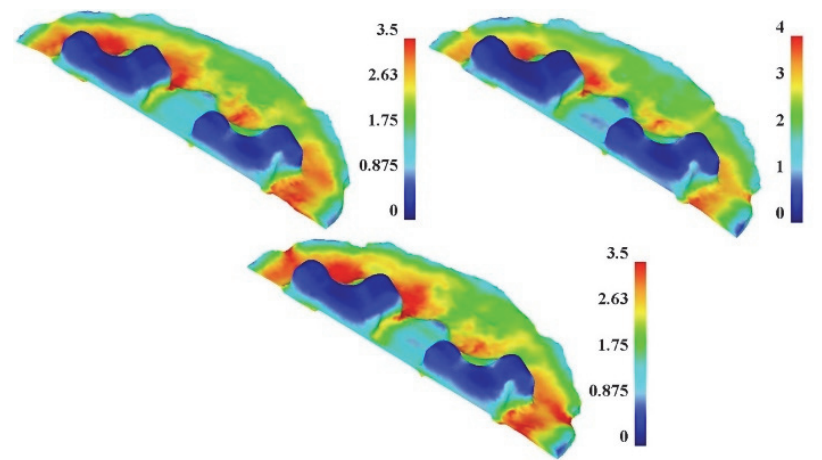

Figure 9 Distribution of the intensity of deformations in the bracket forging (bottom view) forged from the preform with a higher degree of forging on: a) a hydraulic press, b) a drop hammer, c) a screw press
Analysing the area of forgings only, the distributions are qualitatively similar, while the numerical values are slightly divergent. For a hydraulic press, the maximum value of the considered parameter was recorded in the rib (variant I - approximately $420{ }^{\circ} \mathrm{C}$, variant II approximately $410^{\circ} \mathrm{C}$ ). For a drop hammer, the maximum was recorded in the base (variant I approximately $435{ }^{\circ} \mathrm{C}$, variant II approximately $445{ }^{\circ} \mathrm{C}$ ). For the screw press, the temperature distribution was similar and for the base it was about $425^{\circ} \mathrm{C}$.

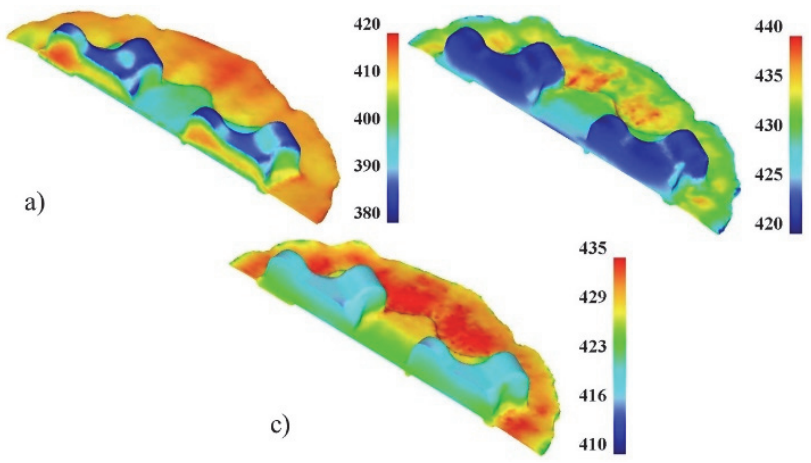

Figure 10 Temperature distribution in the bracket forging (bottom view) forged from the preform with a lower degree of forging on: a) hydraulic press, b) drop hammer, c) screw press

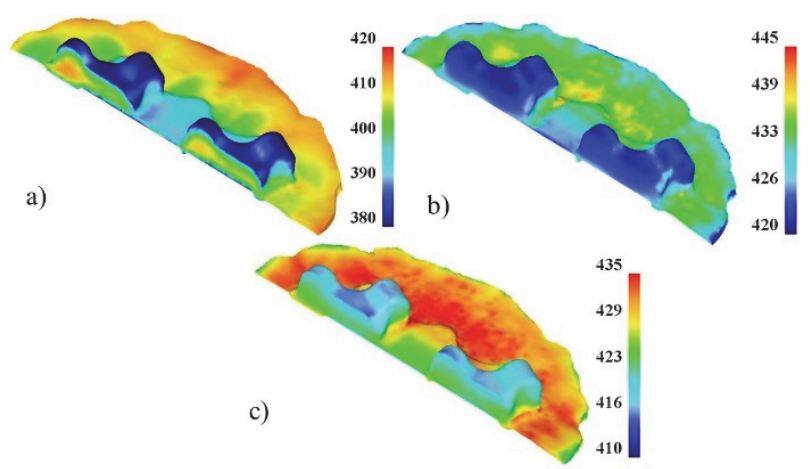

Figure 11 Temperature distribution in the bracket forging (bottom view) forged from the preform with a higher degree of forging on: a) hydraulic press, b) drop hammer, c) screw press

The analysis of the Cockroft-Latham normalised criterion showed that the greatest probability of cracking occurs in the flash, where the criterion value is the highest and amounts to 0,3 for both presses and 0,35 for the hammer. When forging with a hammer, the criterion is higher, which means that the probability of cracking is greater compared to forging with presses.

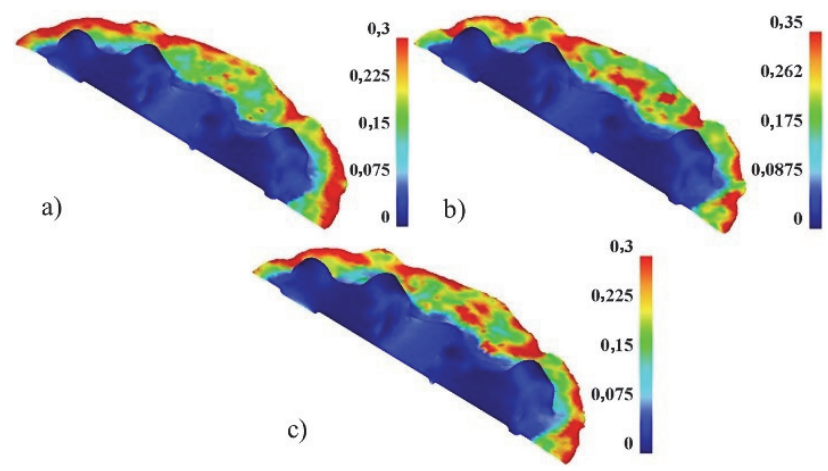

Figure 12 Distribution of the Cockcroft-Latham integral in the bracket forging (bottom view) forged from a preform with a lower degree of forging on: a) a hydraulic press, b) a drop hammer, c) a screw press 


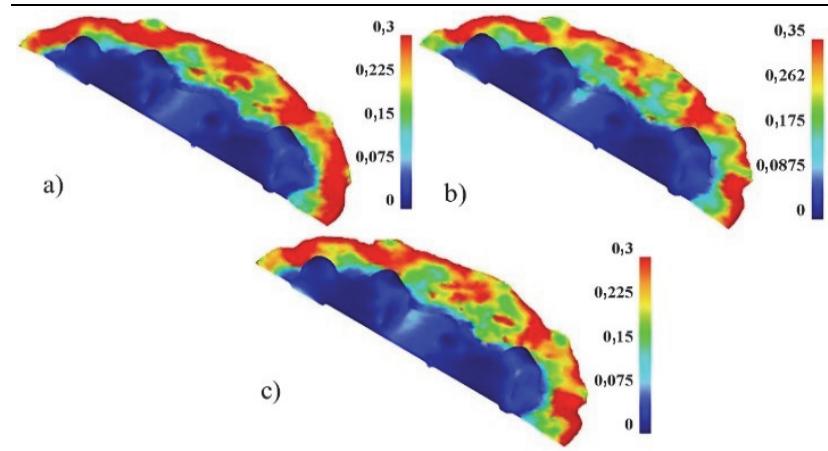

Figure 13 Distribution of the Cockcroft-Latham integral in the bracket forging (bottom view) forged from a preform with a higher degree of forging on: a) a hydraulic press, b) a drop hammer, c) a screw press

In further part of the analysis of the forging technology of the bracket forging made of cast preforms, the graphs are presented indicating the impact energy of the upper die as a function of time for individual preforms for three different machines (Fig. 14 and Fig. 15). There were visible differences between the energy values for the discussed geometric variants of the preforms and the type of the machine on which the process was carried out. For both billet variants (preforms), it was found that the lowest energy needed to carry out the process was obtained for the hydraulic press. The results are similar for the other two machines. Forging a bracket on a hydraulic press from a preform in accordance with the first variant requires the use of less energy (equal to 13,7 kJ) than in the case of forging from a preform in accordance with the second variant; the difference is $3,1 \mathrm{~kJ}$. Also, for the drop hammer and screw press, the required energy (about 16,2 kJ) for the first variant was about $4 \mathrm{~kJ}$ lower than for the second variant.

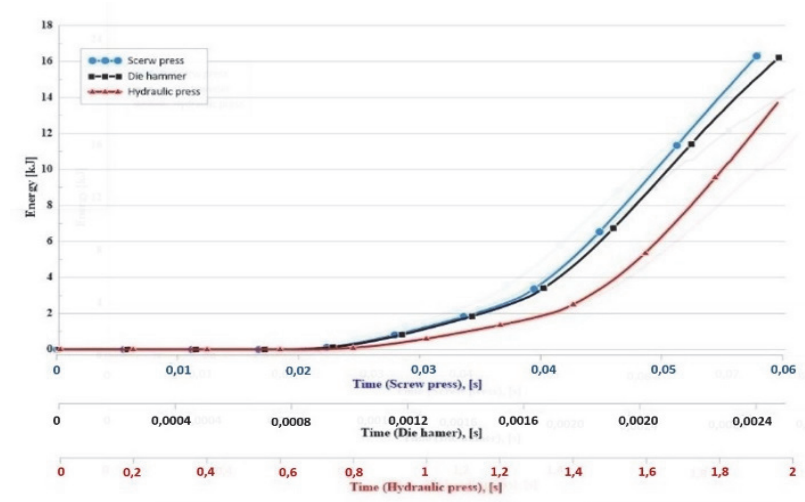

Figure 14 Impact energy of the upper die as a function of time for the forging of the bracket forging from the 1st variant of the preform

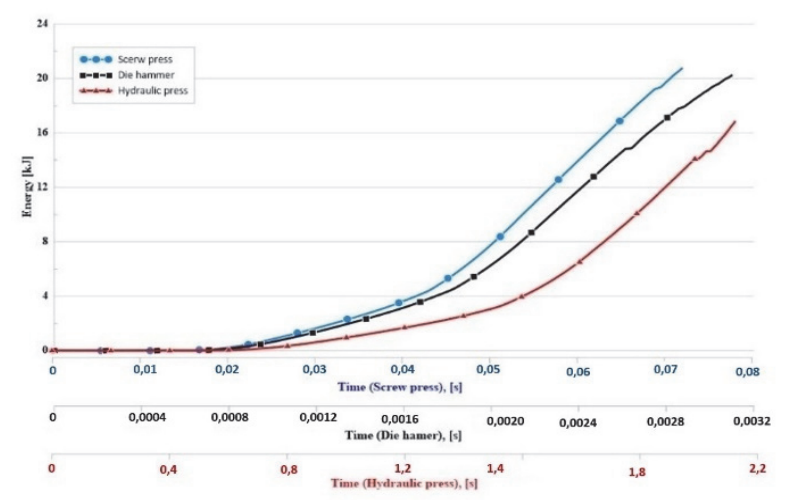

Figure 15 Impact energy of the upper die as a function of time for the forging of the bracket forging from the 2 nd variant of the preform
Fig. 16 and Tab. 2 present a comparative analysis of the volume of the billet's forging, assuming different variants of the process, that is forging from a preform I, preform II and a rod with dimensions of $\varnothing 45 \mathrm{~mm}$ and a length of $160 \mathrm{~mm}$ [4]. The least advantageous in this respect is the process of forging the rod, for which the volume of the material is about $254,469 \mathrm{~mm} 3$ and is greater than the volume of individual preforms by about $18 \%$ for variant I, and $7 \%$ for variant II. The use of preforms reduces the material consumption of the process by $46 \%$ (variant I) and $18 \%$ (variant II) in relation to forging the rod.

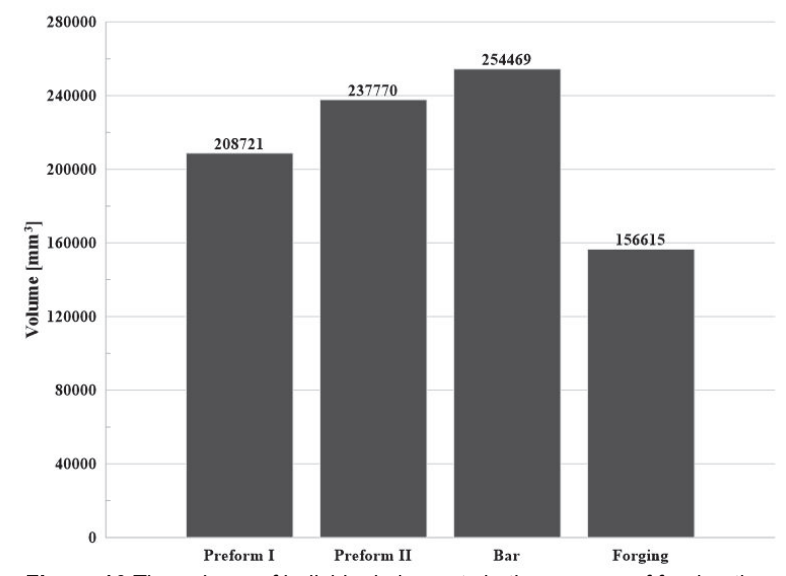

Figure 16 The volume of individual elements in the process of forging the bracket forging preform

Table 2 Percentage of material waste for each bracket forging technology

\begin{tabular}{|c|c|c|}
\hline Geometry & Volume $/ \mathrm{mm}^{3}$ & Waste $/ \%$ \\
\hline Preform I & 208721 & 33,3 \\
\hline Preform II & 237770 & 51,8 \\
\hline Rod-current technology & 254469 & 62,5 \\
\hline Forging & 156615 & - \\
\hline
\end{tabular}

\section{CONCLUSION}

On the basis of the analysis of the forging processes of the bracket forgings made of cast preforms at different rates of deformation on three forging machines (hydraulic press, screw press and drop hammer), the following conclusions were formulated:

- Both geometrical variants of the preforms ensure the correct forgings with the assumed shape and dimensions.

- Forging from a preform according to the first variant is safer in terms of the possibility of loss of material integrity, which is indicated by lower values of the deformation intensity and the Cockcroft-Latham integral.

- The most favourable process parameters were obtained for processes carried out on a hydraulic press.

- The process carried out on a hydraulic press is characterised by lower energy consumption compared to the other two machines by about $18 \%$ for the first variant of the cast preform and by about $22 \%$ for the second variant.

- Forging the bracket forgings from the cast preforms is characterised by a lower material consumption by approximately $18 \%$ (variant I) and $7 \%$ (variant II) than forging directly from a rod. 
- $\quad$ The use of cast preforms reduces material waste by approximately 46 (variant I) and $18 \%$ (variant II) in relation to forging from a rod.

- The numerical analyses carried out confirm the advantages of using computer simulations when developing new technologies $[31,32]$. They make multivariant analysis possible at the process design stage. This allows to analyse the kinematics of material flow in the new process, assess the quality of the obtained geometry of the product, analyse the process in terms of: state of stress, deformation, cracking, and plan experimental studies more precisely as well as reduce their costs.

- The correctness of the modelled geometry of cast preforms should be verified in experimental tests.

\section{Acknowledgements}

Project "The Design and Implementation of an Innovative Low-Waste Metal Forming Technology for High-Strength Light Metal Alloys Used in the Aircraft and Automotive Industry"; No. LIDER/10/0058/L8/16/NCBR/2017. Total cost of the Project: 1,200,000 PLN. The project is financed by the National Centre for Research and Development under the 8th edition of the LIDER Programme.

\section{REFERENCES}

[1] Czyz, Z., \& Karpinski P. (2020). Aerodynamic Characteristics of the X-Tail Stabilizer in a Hybrid Unmanned Aircraft. International Journal of Simulation Modelling, 19(4), 631-642. https://doi.org/10.2507/IJSIMM19-4-534

[2] Khawaja, A. H., Jahanzaib, M., \& Cheema, T. A. (2020). High-speed machining parametric optimization of 15 CDV6 HSLA steel under minimum quantity and flood lubrication. Advances in Production Engineering \& Management, 15(4), 403-415. https://doi.org/10.14743/apem2020.4.374

[3] Roca-Gonzalez, J. L., Vera-Lopez, J. A., \& RodriguezBermudez, G. (2018). Analysis of Patent \#US2014/0319274A1: a Case Study of Simulations for New Designs Review. International Journal of Simulation Modelling, 17(3), 405-418. https://doi.org/10.2507/IJSIMM17(3)433

[4] Drozdowski, K. (2015). Studies on drop forging of magnesium alloys on screw presses and forging hammers. Lublin, Doctoral thesis Lublin University of Technology.

[5] Kudła, K., Iwaszko, J., \& Strzelecka, M. (2017).Surface modification of AZ91 magnesium alloy using GTAW technology. The Bulletin of the Polish Academy of Sciences: Technical Sciences, 65(6), 917-926. https://doi.org/10.1515/bpasts-2017-0099

[6] Cagan, S. C., Aci, M., Buldum, B. B., \& Aci, C. (2019). Artificial neural networks in mechanical surface enhancement technique for the prediction of surface roughness and microhardness of magnesium alloy. The Bulletin of the Polish Academy of Sciences: Technical Sciences, 67(4), 729-739.

[7] Górny, Z. \& Sobczak, J. (1997).Modern foundry plastics based on non-ferrous metals. Cracow: Special Edition of the Foundry Research Institute in Cracow.

[8] Fajkiel, A., Białobrzeski, A., Dudek, P., \& Reguła, T. (2009). Modern magnesium alloys and casting methods for automotive applications. Cracow: Special Edition of the Foundry Research Institute in Cracow.

[9] Reguła, T., Bronicki, M., Lech-Grega, M., \& Czekaj, E. (2008). Assessment of the possibility of forming the mechanical properties of AZ91 magnesium alloy casting by means of an appropriate heat treatment.Transactions of Foundry Research Institute, XLVIII (1), 40-42.

[10] Ziółkiewicz, S., Jankowski, Ł., \& Gronowski, W. (2013). Forming of cast AZ91 magnesium alloy on the background of coextrusion tests. Metal Forming, XXIV (2), 109-117.

[11] Pachutko, B. \& Ziółkiewicz, S. (2013). Metallographic investigation of cast AZ91 magnesium alloy after coextrusion.Metal Forming, XXIV (2), 119-129.

[12] Bulzak, T., Tomczak, J., \& Pater, Z. (2015).Theoretical and experimental research on forge rolling process of preforms from magnesium alloy AZ31. Archives of Metallurgy and Materials, 60(1), 437-443. https://doi.org/10.1515/amm-2015-0072

[13] Pater, Z., Tomczak, J., Bulzak, T., Bartnicki, J. \&Tofil, A. (2019). Prediction of crack formation for cross wedge rolling of harrow tooth preform. Materials, 14(12). https://doi.org/10.3390/ma12142287

[14] Biba, N., Vlasov, A., Krivenko, D., Duzhev, A., \& Stebunov, S. (2020). Closed die forging preform shape design using isothermal surfaces method.Procedia Manufacturing, 47, 268-273. https://doi.org/10.1016/j.promfg.2020.04.219

[15] Wang, S. I., Seo, M. K., Cho, J. R., \& Bae, W. B. (2002). A study on the development of large aluminum flange using the casting/forging process. Journal of Materials Processing Technology, 130-131, 294-298. https://doi.org/10.1016/S0924-0136(02)00809-9

[16] Płonka, B., Kłyszewski, A., Senderski, J., \& Lech-Grega, M. (2008). Application of $\mathrm{Al}$ alloys, in the form of cast billet, as stock material for the die forging in automotive industry. Archives of Civil and Mechanical Engineering, 2(8), 149156. https://doi.org/10.1016/S1644-9665(12)60201-5

[17] Krüger, L., Jentsch, E., Brunke, L., Keßler, A., Wolf, G., Lehnert, T., Schubert, N., Wagner, A., \& Landgrebe, D. (2019). Development of an innovative lightweight piston through process combination casting-forging.Procedia Manufacturing, 27, 172-176. https://doi.org/10.1016/.promfg.2018.12.061

[18] Wang, P., Zhu, S., Wang, L., Wu, L.. \& Guan, S. (2015). A two-step superplastic forging forming of semi-continuously cast AZ70 magnesium alloy. Journal of Magnesium and Alloys, 3, 70-75. https://doi.org/10.1016/j.jma.2014.12.004

[19] Demlera, E., Götze, S., Herbst, S., Nürnberger, S., Maier, H. J., Ursinus, J., Büdenbender, Ch., \& Behrens, B. A. (2020). Casting manufacturing of cylindrical preforms made of low alloy steels. Procedia Manufacturing, 47, 445-449. https://doi.org/10.1016/j.promfg.2020.04.333

[20] Ursinus, J., Bonhage, M., Budenbender, Ch., Nurnberger, F., Demler, E., \& Behrens, A. (2019). Hot forming of cast steel cylinders. Metals, 501-506. https://doi.org/10.37904/metal.2019.820

[21] Płonka, B., Lech-Grega, M., Remsak, K., Korczak, P., \& Kłyszewski, A. (2013). Die forging of high-strength $\mathrm{Mg}$ alloys-Structure and mechanical properties in various states of heat treatment. Archives of Metallurgy and Materials, 1(58), 127-132. https://doi.org/10.2478/v10172-012-0162-9

[22] Wang, Q., Zhang, Z., Zhang, X., \& Li, G. (2010). New extrusion process of $\mathrm{Mg}$ alloy automobile wheels. Transactions of Nonferrous Metals Society of China, 20, 599-603. https://doi.org/10.1016/S1003-6326(10)60546-8

[23] Shan, D., Xu, W., Han, X., \& Huang, X. (2012). Study on isothermal precision forging process of rare earth intensifying magnesium alloy. Materials Science and Engineering: B, 19(177), 1698-1702. https://doi.org/10.1016/j.mseb.2011.10.006

[24] Gontarz, A., Drozdowski, K., Michalczyk, J., Wiewiórowska, S., Pater, Z., Tomczak, T., Samołyk, G., Winiarski, G., \& Surdacki, P. (2021).Forging of Mg-Al-Zn Magnesium Alloys on Screw Press and Forging Hammer Examples. Materials, 14. https://doi.org/10.3390/ma14010032 
[25] Gontarz, A., Pater, Z., Drozdowski, K., \& Doleba, R. (2012). Theoretical verification of the die forging process of the AZ80 magnesium alloy lever forgings. Ores and non-ferrous metals, 57(5), 305-311.

[26] Kuc, D., Bednarczyk, I., Hadasik, E., \& Niewielski, G. (2011). Plasticity tests of magnesium alloy WE43. Metallurgy-Metallurgical News, 8, 637-640.

[27] Tomczak, J. \& Bartnicki, J. (2012). Machines and devices for metal forming. Lublin: Lublin University of Technology.

[28] Pater, Z. \& Samołyk, G. (2013). Fundamentals of metal forming technology. Lublin: Lublin University of Technology.

[29] Wasiunyk, P. (1987). Die forging. Warsaw: Scientific and Technical Publishers.

[30] Palaniswamy, H., Ngaile, G., \& Altan, T. (2004). Finite element simulation of magnesium alloy sheet forming at elevated temperatures. Journal of Materials Processing Technology, 145(1), 52-60. https://doi.org/10.1016/S0924-0136(03)00844-6

[31] Dziubińska, A., Gontarz, A., \& Zagórski, I. (2018). Qualitative research on AZ31 magnesium alloy aircraft brackets with a triangular rib produced by a new forging method. Aircraft Engineering and Aerospace Technology, 90(3), 482-488. https://doi.org/10.1108/AEAT-09-2016-0160

[32] Dziubińska, A. \& Gontarz, A. (2015). Limiting phenomena in a new forming process for two-rib plates. Metalurgija, 54(3), 555-558.

\section{Contact information:}

\section{Anna DZIUBIŃSKA, PhD}

(Corresponding author)

Department of Computer Modelling and Metal Forming Technologies,

Faculty of Mechanical Engineering,

Lublin University of Technology, 20-618 Lublin, Poland

E-mail: a.dziubinska@pollub.pl

\section{Piotr SURDACKI, M.Sc.}

Department of Computer Modelling and Metal Forming Technologies,

Faculty of Mechanical Engineering,

Lublin University of Technology, 20-618 Lublin, Poland

E-mail: piotr.surdacki@pollub.pl 